BMJ

Open

Gastroenterology

\section{Accuracy and comparison of two rapid multiplex PCR tests for gastroenteritis pathogens: a systematic review and meta-analysis}

To cite: Chang L-J, Hsiao C$\mathrm{J}$, Chen B, et al. Accuracy and comparison of two rapid multiplex PCR tests for gastroenteritis pathogens: a systematic review and metaanalysis. BMJ Open Gastro 2021;8:e000553. doi:10.1136/ bmjgast-2020-000553

- Prepublication history and additional material is published online only. To view please visit the journal online (http://dx.doi. org/10.1136/bmjgast-2020000553).

L-JC and C-JH contributed equally.

Received 14 0ctober 2020 Revised 7 January 2021 Accepted 13 January 2021

\section{Check for updates}

(c) Author(s) (or their employer(s)) 2021. Re-use permitted under CC BY-NC. No commercial re-use. See rights and permissions. Published by BMJ.

For numbered affiliations see end of article.

Correspondence to Professor Chien-Chang Lee; cclee100@gmail.com

\section{ABSTRACT}

Objectives The primary aim is to provide a summary of evidence for the diagnostic accuracies of multiplex PCR gastrointestinal (Gl) panels-BioFire FilmArray and Luminex XTAG on the detection of gastroenteritis pathogens. The secondary aim is to compare the performance of these Gl panels head to head. Methods A comprehensive search up to 1 December 2019 was conducted on PubMed, Embase, Ovid Medline and Web of Science for studies that used FilmArray or Luminex xTAG Gastrointestinal Pathogen Panel (GPP) for diagnosis of acute gastroenteritis. A summary of diagnostic accuracies for the 16 pathogens were calculated by comparing the Gl panels to the current gold standards (conventional standard microbiology techniques such as culture or PCR for bacteria, PCR or enzyme immunoassay (EIA) for viruses, microscopy or EIA for parasite). Hierarchical summary receiver operating characteristic (HSROC) curve analysis, pretest and posttest probabilities were used for estimating the pathogen detection performance.

Results A total of 11 studies with 7085 stool samples were eligible for analysis. Multiplex PCRs demonstrated high diagnostic accuracy, with specificity $\geqq 0.98$ and area under the ROC curve (AUROC) $\geqq 0.97$ for all the pathogens except for Yersinia enterocolitica (AUROC 0.91). The FilmArray panel demonstrated a higher sensitivity than XTAG GPP for most of the pathogens with the exception of Rotavirus A (XTAG GPP and FilmArray were both 0.93 ). Conclusions This is the first meta-analysis that is a head-to-head comparison examining the performance of the novel multiplex PCR-based tests Luminex xTAG GPP and FilmArray Gl panel in detecting each pathogen. Point estimates calculated from eligible studies showed that both GI panels are highly accurate and may provide important diagnostic information for early identification of gastroenteritis. In addition, although FilmArray has higher sensitivity and post-test probability than XTAG GPP for most of the pathogens, how this will translate to a clinical setting remains unclear.

\section{INTRODUCTION}

Every year, there are about 2 billion cases of diarrhoeal disease worldwide. ${ }^{1}$ Most cases of
Summary box

What is already known about this subject?

- Recently, there has been tremendous interest in the development of multiplex molecular assays for the rapid detection and identification of pathogens responsible for causing diarrhoeal illness. Our review focuses on the first two Food and Drug Association-approved multiplex assays: FilmArray Gastrointestinal (GI) Panel and Luminex XTAG Gastrointestinal Pathogen Panel (GPP).

What are the new findings?

- Our study found that both FilmArray and GPP have high diagnostic accuracy. However, in comparison to GPP, the FilmArray GI panel demonstrated superior performance with higher sensitivity and summary area under the receiver operating characteristic curve than XTAG GPP. While there is significant statistical difference in their performances, how this will translate to a clinical setting remains unclear.

How might it impact on clinical practice in the foreseeable future?

- These results are essential to guide the advancement of multiplex technology and its implementation in the clinical world as our study suggests that multiplex assays can significantly enhance diagnostic output in the evaluation of acute diarrhoeal illness.

gastroenteritis are due to infections which include viral, bacterial and, less frequently, parasitic. Norovirus is the most common cause of acute gastroenteritis in young children and infants in the USA, ${ }^{2}$ while severe diarrhoea is typically associated with bacterial causes. ${ }^{3}$ Furthermore, infectious diarrhoea is a frequent and serious complication in immunocompromised patients. ${ }^{4}$ As diarrhoeal diseases remain a leading cause of morbidity and mortality worldwide, the rapid accurate diagnosis of the underlying pathogen is 
crucial for identifying any potential complications and to optimise treatment, particularly in patients with severe illness, significant comorbidities or high-risk features. ${ }^{56}$

Conventional diagnostic methods, such as stool cultures, enzyme immunoassays (EIA) and one-target PCR assays, are time-consuming, laborious and operator dependent. ${ }^{7}$ In light of these limitations, the development of multiplex molecular assays has generated considerable interest. Multiplex molecular assays rapidly detect a wide range of bacterial, viral and parasitic pathogens simultaneously, reducing turnaround time and allowing for detection of coinfections. There are a number of US Food and Drug Association (FDA)-cleared multiplex panels available today for detecting gastrointestinal (GI) pathogens, each with pros and cons. Particularly, the FilmArrayGI Panel and the Luminex xTAG Gastrointestinal Pathogen Panel (GPP), which are the first two FDA-approved multiplex assays. The FilmArray GI panel is a qualitative, highly multiplexed PCR test that targets 22 pathogens (13 bacterial, 5 viral and 4 parasitic) from stool samples. ${ }^{8}$ On the other hand, the Luminex xTAG GPP is a multiplexed molecular test for 15 GI pathogens (9 bacterial, 3 viral and 3 parasitic) with overall sensitivity and specificity greater than $90 \%$ compared with conventional methods.

In addition, FilmArray is a Clinical Laboratory Improvement Amendments (CLIA) -waived end-to-end system that requires minimal hands-on processing time $(2 \mathrm{~min}$ per run) and offers a rapid turnaround time ( 1 hour per run), making it suitable for use in the points of care outside the central laboratory, such as clinic, emergency room and military. In contrast, xTAG GPP, although a longer turnaround time of 3.5 hours, can analyse 96 samples at a time and accommodate 192 samples in a shift of 7-8hours, making it optimal for high-volume reference laboratories.

Studies have shown, however, that the diagnostic accuracy for each pathogen varies among the different multiplex platforms. ${ }^{10}$ Therefore, the primary aim of this systematic review and meta-analysis is to evaluate the diagnostic value and reliability of xTAG GPP and FilmArray in detecting GI infections, and the secondary aim is to compare the diagnostic accuracies of xTAG GPP and FilmArray GI panel for each pathogen.

\section{METHODS}

The protocol of our study was based on the Preferred Reporting Items for Systematic Reviews and Metaanalyses(PRISMA) statement ${ }^{11}{ }^{12}$ and the standard guideline for systematic reviews of diagnostic tests by the Cochrane Collaboration.

\section{Search strategy}

A comprehensive search of literature was conducted using three databases: PubMed (from January 2016 to Dec 2019), Embase (from January 2016 to Dec 2019), Ovid Medline (from January 2016 to Dec 2019) and
Web of Science (from January 2016 to Dec 2019). The detailed search strategy is provided in online supplemental material S1. The search was then supplemented by manual searching of bibliographies of retrieved fulltext articles and the latest narrative reviews. The articles before 2016 were supplemented by a previous systematic review. ${ }^{8}$

\section{Study selection}

Studies were included if they (1) included patients with acute diarrhoea, suspected secondary to infectious gastroenteritis, with tests (stool samples) from hospitals or clinics; (2) assessed the accuracy of xTAG GI panel or FilmArray GI panel; (3) used conventional standard microbiology techniques as comparators, such as culture or PCR for bacteria, PCR or EIA for viruses and microscopy or EIA for parasites and (4) provided sufficient information to calculate sensitivity and specificity. Studies were excluded if they (1) only analysed confirmed positive specimens without negative controls, (2) included spiked samples or swab testing, or (3) used other partial multiplex tests. We excluded reviews, case reports, editorials and opinions, letters, poster presentations without supporting abstracts or meeting abstracts without sufficient details on test performance. Two reviewers independently screened the titles and abstracts. Disagreements or uncertainties were resolved by consensus meeting after discussion with the senior author (C-CL).

\section{Data extraction}

We extracted the following characteristics for analysis: author, publish year, article title, country, data collecting time, clinical setting, mean age, case number, male proportion, GI panel used, pathogens, sensitivity, specificity, patient inclusion criteria, gold standard or reference. The $2 \times 2$ tables were further used to calculate sensitivities and specificities of the target assays. For the reference methods, conventional standard microbiology techniques, such as culture or PCR for bacteria, PCR or EIA for viruses, microscopy or EIA for parasites were grouped together because they are universally recognised as the reference standard ${ }^{8}$ Composite reference standard was defined as a standard that used more than one comparator assays. Children were defined as patients younger than 18 years. Studies that included both children and adult population were categorised as mixed population. There are five studies that included discordant analysis. Discordant analysis means further analysing discordant results between routine reference tests and GI panels using an additional method, such as singleplex PCR, sequencing or other multiplex panels, to confirm the final results. Samples were considered true positives if they tested positive by both routine reference tests and GI panels and did not require additional testing. Samples were considered true negative if they tested negative by both routine reference tests and GI panels. 
Quality assessment

The quality of the eligible studies was independently assessed by two reviewers using the Quality Assessment of Diagnostic Accuracy Studies 2 tool (QUADAS-2). ${ }^{13}$ Any disagreements were resolved by consensus or arbitration. Assessment was done across 4 domains of bias (patient selection, index test, reference standard and flow and timing). For each diagnostic study, we determined the risk for bias and general applicability in all four domains of QUADAS-2 and reported them separately. Those with low risk of bias or low concern regarding applicability were judged as low. A study would be judged as unclear if there were insufficient data for interpretation. We added several questions to evaluate the quality of included studies. The tailored QUADAS-2 form and guidance notes are provided in online supplemental material S2.

\section{Data synthesis and statistical analysis}

A bivariate random effect model was applied to estimate summary sensitivity and specificity with $95 \%$ CIs. ${ }^{14}$ The positive likelihood ratios (LR+) and negative LR (LR-) were then calculated from summary sensitivity and specificity. The bivariate model approach modelled the sensitivity and specificity simultaneously to account for the inherent negative correlation between sensitivity and specificity that may arise due to different thresholds in different studies. In addition, the bivariate model could also account for between-study heterogeneity. We constructed a hierarchical summary receiver operating characteristic (HSROC) curve and calculated the area under the ROC curve (AUROC). ${ }^{15}$ Fagan plot analyses were conducted to infer positive and negative post-test probabilities. A pretest probability of the pathogen was estimated by the number of symptomatic cases in selected studies. The degree of between-study heterogeneity was calculated using the $\mathrm{I}^{2}$ test. ${ }^{16}$ A two-sided $\mathrm{p}<0.05$ indicates statistical significance for all tests. All analyses except for the summary ROC were performed by the 'mada' package in $\mathrm{R}$ software ( $\mathrm{R}$ Foundation for Statistical Computing, Vienna, Austria; http://www.r-project. org/). The summary ROC and AUROC was calculated by the 'midas' package in STATA cer V.11 (STATA).

\section{RESULTS}

\section{Identification of studies}

After two rounds of inclusion and exclusion (figure 1), 11 studies with 21 data sets and 7085 stool samples were included in this analysis. Different studies were consolidated as one data set if they compared the same multiplex

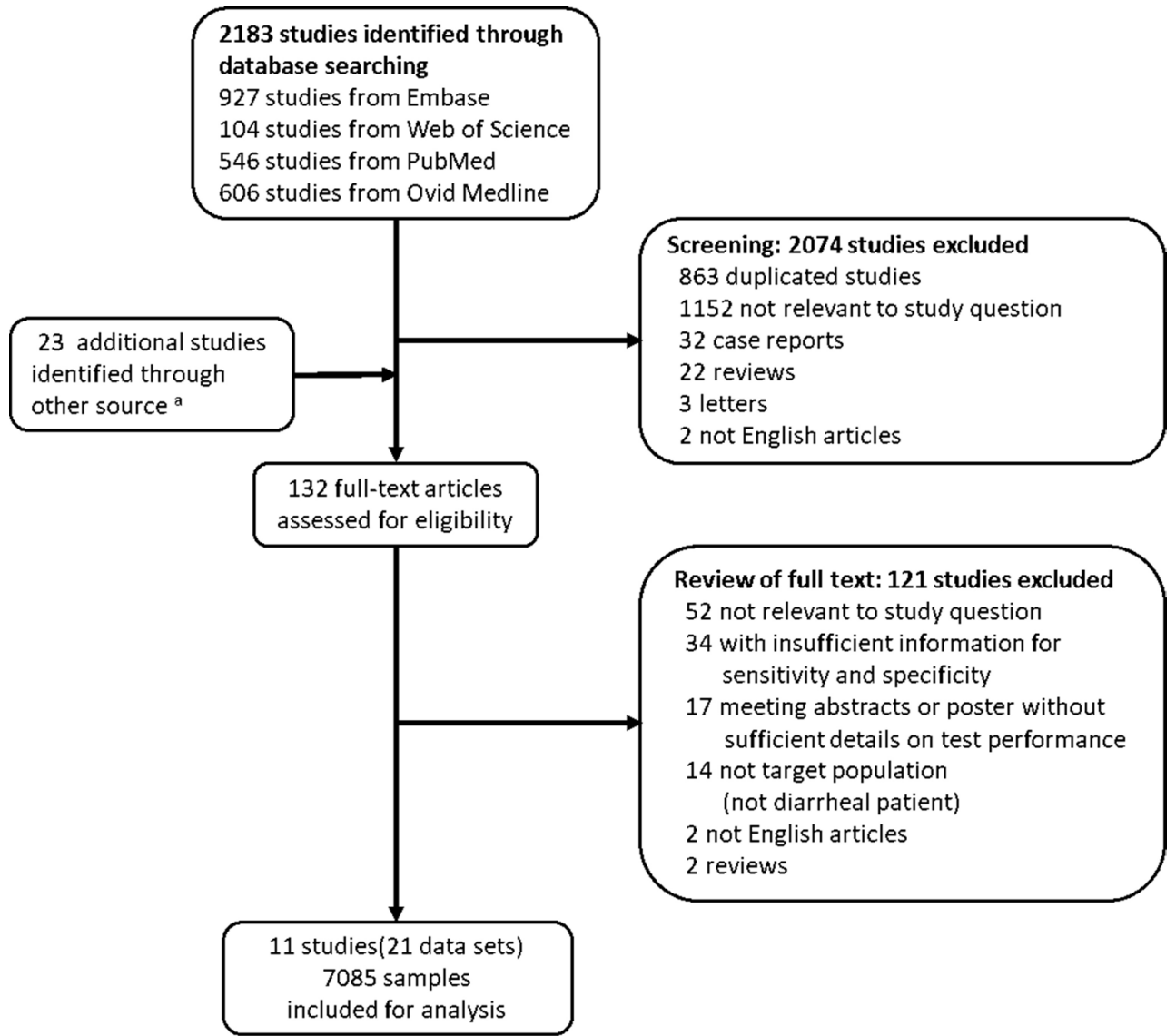

Figure 1 PRISMA flow diagram for selection of articles for meta-analysis. ${ }^{\text {aThese }} 23$ additional studies were identified from the inclusion studies of a systematic review: multiplex tests to identify gastrointestinal bacteria, viruses and parasites in people with suspected infectious gastroenteritis: a systematic review and economic analysis. The systematic review had the same inclusion and exclusion criteria as our study, and included the articles published before 2015. PRISMA, Preferred Reporting Items for Systematic Reviews and Meta-analyses. 
platforms using the same patient group and reference methods. The number of data sets is regarded as two if a study compared two different multiplex platforms to conventional techniques or applied one multiplex platform to two different patient groups.

\section{Characteristics of included studies}

The characteristics of eligible studies are summarised in table 1 , and the summary was provided in online supplemental material S3. One data set included exclusively adult patients, ${ }^{4}$ two data sets (from one study) recruited children only $^{17}$ and the majority of studies studied on mixed adult and children populations. Luminex xTAG GPP was used in 15 data sets $(71 \%)$, while FilmArray GI panel was used in six data sets (29\%). Both conventional microbiology techniques and molecular methods such as sequencing or real-time PCR were commonly employed reference standards. Nine studies with 15 data sets used the GI panel on prospectively collected samples from patients with suspected gastroenteritis ${ }^{479} 10$ 18-22 while two studies (four data sets) evaluated the GI panel retrospectively. ${ }^{25}$ One study (two data sets) included both retrospective and prospectively collected samples. ${ }^{17}$ The comparison of FDA-approved GI panels included in our study are listed in online supplemental material S4. ${ }^{10}$ In general, the Luminex xTAG GPP has to be operated in a central laboratory with higher throughput (96 samples per round) but a longer turnaround time of 3.5 hours. The FilmArray system is a point-of-care machine that can complete the analysis within 1 hour but can only test 1 sample per round. Details of the characteristics and key results of each individual study are provided in online supplemental material S3 and S5).

\section{Quality assessment}

Quality assessment by the QUADAS-2 tool is demonstrated in figure 2. For the 'Patient Selection' domain, some studies used samples with known etiologies from microbiological culture; others did not avoid a casecontrol design. For the 'Index Test' domain, the index test used in all the studies was performed independently and the threshold was prespecified within the GPP test. For the 'Reference Standard' domain, all patients received the reference standard tests, with minimal risk of verification bias. The reference standard was independent of the index test, and the interpretation threshold was prespecified, therefore, the risk of incorporation bias is low. Overall, all the studies had low concern regarding applicability for index tests. Regarding applicability of the reference standard, studies using singleplex PCR or sequencing as the standard raise concern because it may detect pathogens at levels that are unlikely to cause symptoms. Some studies included immunocompromised patients or travellers and could raise concerns on the applicability to the general population.

\section{Diagnostic accuracy of GI panel}

Table 2 lists the point estimates of sensitivity, specificity, AUROC the HSROC, LR+, LR-, publication bias and $\mathrm{I}^{2}$ for each pathogen. All pathogens had a high discrimination (AUROC $\geq 0.96$ ) by the two GI panel tests except for Yersinia enterocolitica by xTAG GPP (AUROC: 0.91). The specificity of the two GI panel tests were high, ranging from 0.98 to 1.00 , except for Salmonella by xTAG GPP (Spe: 0.97) and Clostridium difficile by FilmArray (Spe: $0.97)$. The sensitivities were all greater than 0.81 with majority $>0.90$, except for $Y$. enterocolitica (Sen:0.48), Adenovirus 40/41 (Sen: 0.70) and Entamoeba histolytica (Sen: 0.70 ) by xTAG GPP. FilmArray panel demonstrated a higher sensitivity than xTAG GPP for most of the pathogens with the exception of Rotavirus A (xTAG GPP and FilmArray are both 0.93 ). The overall LR+ was well beyond 10 , indicating a high rule-in value of the positive test results. The LR- for FilmArray were all $\leq 0.1$, lower than xTAG GPP for all pathogens except for Rotavirus, suggesting a higher rule-out value for FilmArray panel than xTAG GPP. (Online supplemental materials S6 and S7 illustrate the HSROC curves for each pathogen by xTAG GPP (online supplemental material S6) and FilmArray (online supplemental material S7). Online supplemental material S8 shows the forest plot of sensitivity and specificity of the GI panel for each pathogen.

Table 3 showed the pretest and post-test probability for each pathogen tested by GI panels. The post-test probability for positive test across all the pathogens tested by xTAG GPP varied between $11 \%$ and $86 \%$; for FilmArray, the post-test probability for positive test varied between $68 \%$ and $96 \%$ (table 3). xTAG GPP demonstrated a poor positive post-test probability on E. histolytica, Giardia lamblia, Cryptosporidium and ETEC (11\%, 25\%, 40\% and $42 \%$, respectively). FilmArray has better post-test probability than xTAG GPP except for Rotavirus A (the posttest probability for positive test is $69 \%$ for FilmArray, $86 \%$ for XTAG) (table 3 ). $\mathrm{I}^{2}$ was $>50 \%$ in most of the analyses. Lastly, we pooled 10 studies of xTAG GPP and 6 studies of FilmArray GI panel and plotted the HSROC of two GI panel tests (online supplemental material S9). The FilmArray GI panel showed a higher AUROC than xTAG GI panel (AUROC 0.99 vs $0.98, p=0.03$ ). Online supplemental material S10 shows subgroup analysis for GI panel sensitivity and specificity when tested with different gold standards on Campylobacter, Shigella and rotavirus A. The result showed that the $\mathrm{p}$ values were all $>0.1$, which indicated that there were no significant differences between the overall results and the subgroups.

\section{DISCUSSION}

Our study found that both FilmArray and xTAG GPP have high diagnostic accuracies. To our knowledge, this is the first meta-analysis of a head-to-head comparison between the two currently available commercial multiplex PCR tests for GI pathogens. In this meta-analysis consisting of 7085 stool samples, we show that both systems have a nearly perfect specificity with high LR+, indicating a high rule-in value. The sensitivities and LR-, however, vary between the two systems. The FilmArray GI 


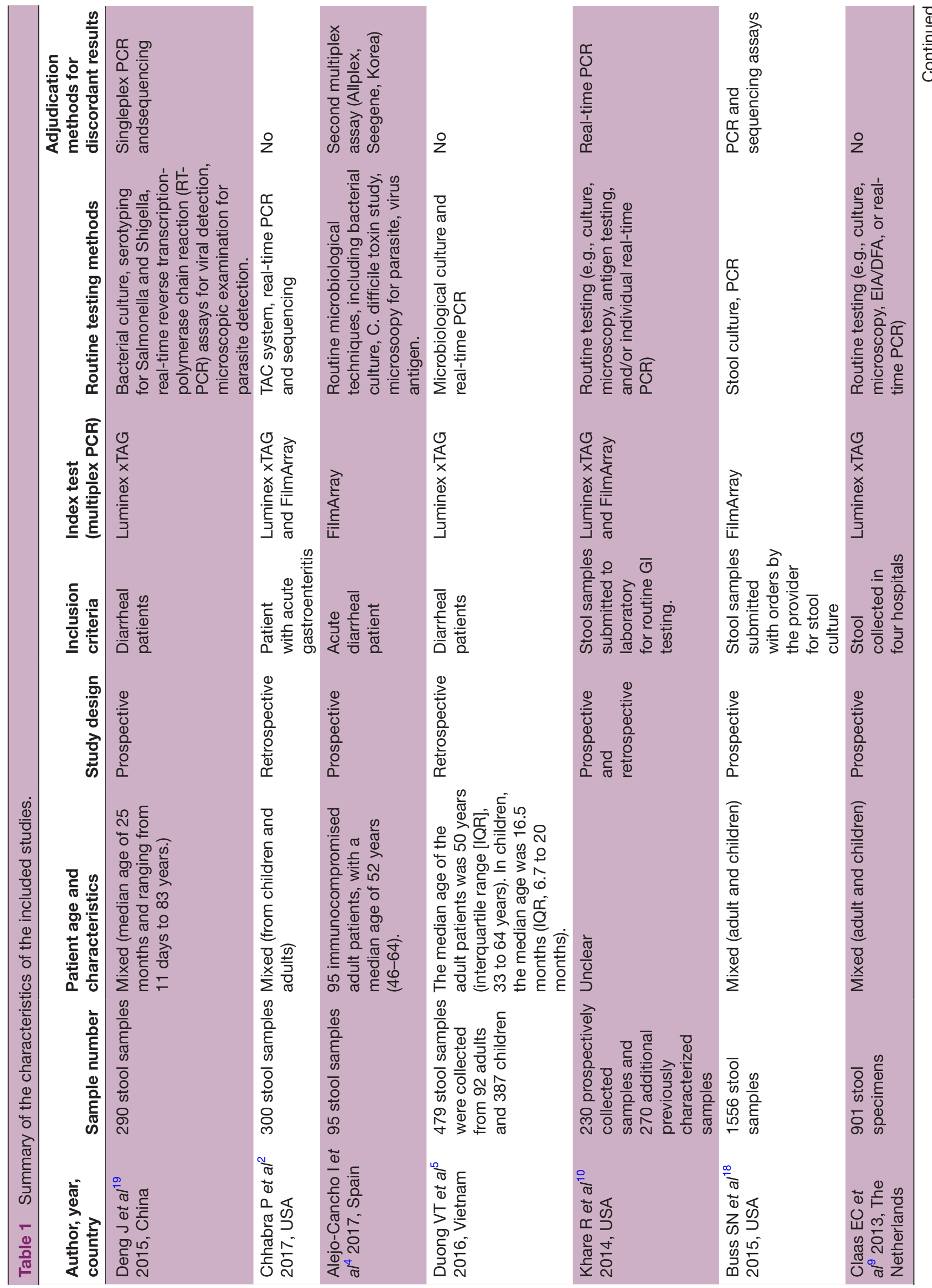




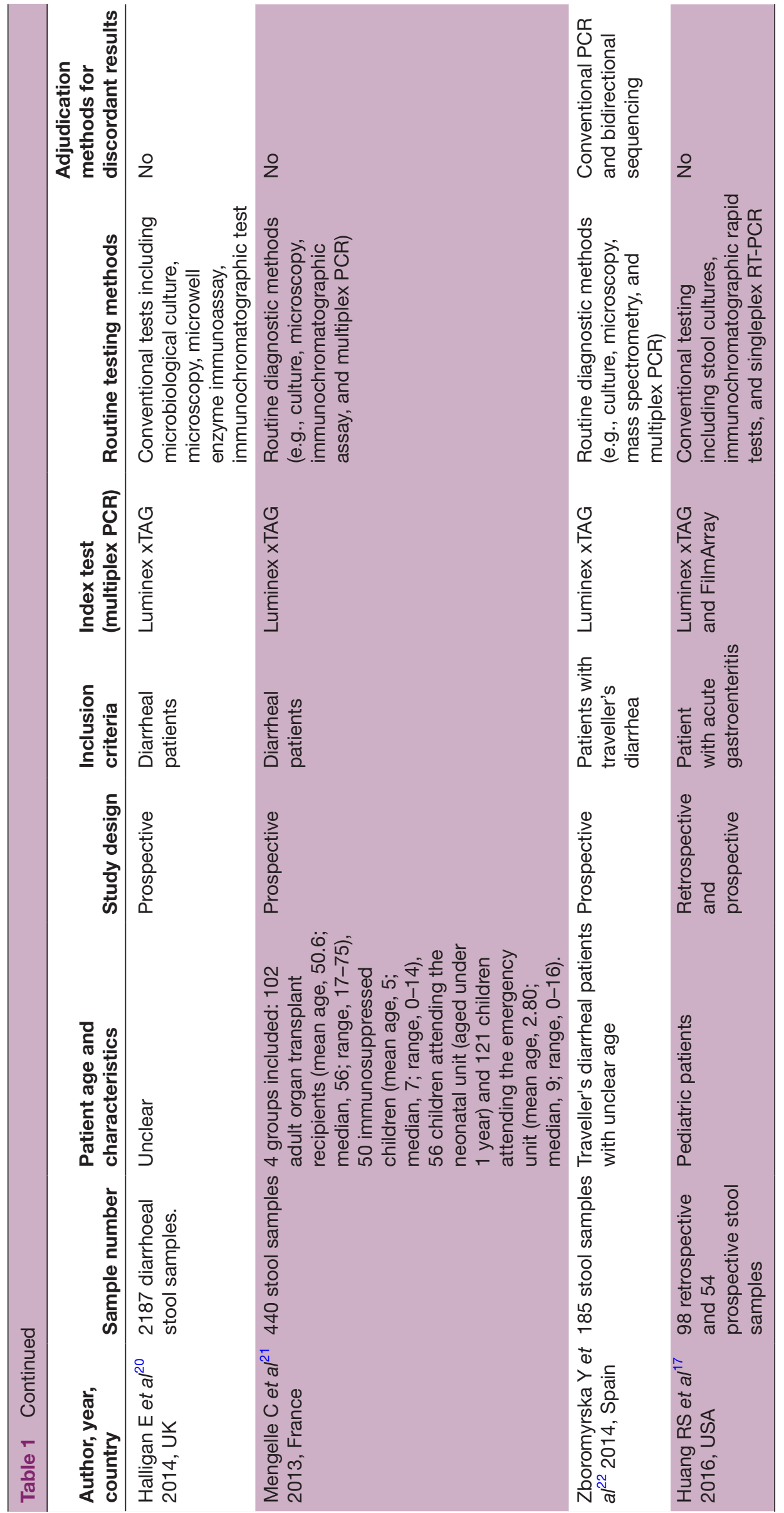




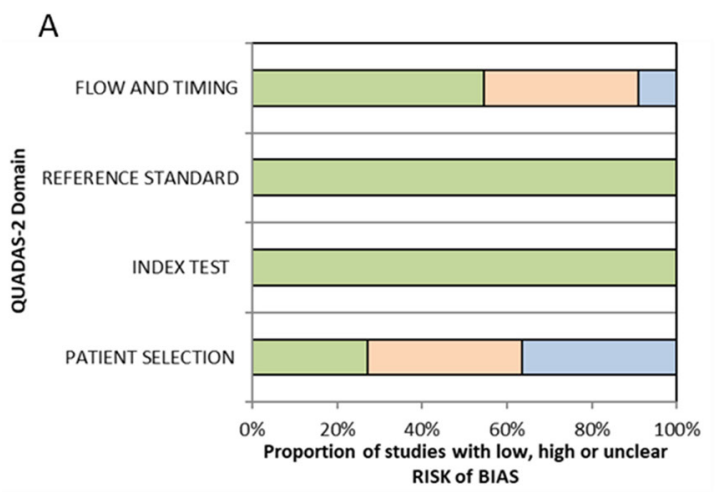

¿Low $\square$ High QUnclear

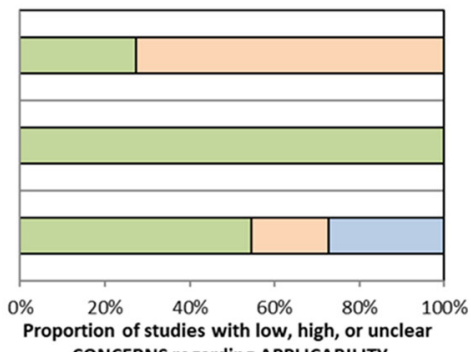

CONCERNS regarding APPLICABILITY

B Risk of Bias

\begin{tabular}{|c|c|c|c|c|}
\cline { 2 - 5 } \multicolumn{1}{c|}{ STUDY } & $\begin{array}{c}\text { PATIENT } \\
\text { SELECTION }\end{array}$ & $\begin{array}{c}\text { INDEX } \\
\text { TEST }\end{array}$ & $\begin{array}{c}\text { REFERENCE } \\
\text { STANDARD }\end{array}$ & $\begin{array}{c}\text { FLOW AND } \\
\text { TIMING }\end{array}$ \\
\hline Deng J, 2015, China & Low & Low & Low & Low \\
\hline Chhabra P, 2017, USA & High & Low & Low & Low \\
\hline Alejo-Cancho I, 2017, Spain & Low & Low & Low & Low \\
\hline Duong VT, 2016, Vietnam & High & Low & Low & Low \\
\hline Khare R, 2014, USA & Unclear & Low & Low & High \\
\hline Buss SN, 2015, USA & Unclear & Low & Low & Low \\
\hline Claas EC, 2013, Netherlands & Unclear & Low & Low & Unclear \\
\hline Halligan E, 2014, UK & Unclear & Low & Low & High \\
\hline Mengelle C, 2013, France & High & Low & Low & High \\
\hline Zboromyrska Y, 2014, Spain & Low & Low & Low & High \\
\hline Huang RS, 2016, USA & High & Low & Low & Low \\
\hline
\end{tabular}

Concerns regarding applicability

\begin{tabular}{|c|c|c|}
\hline $\begin{array}{c}\text { PATIENT } \\
\text { SELECTION }\end{array}$ & $\begin{array}{c}\text { INDEX } \\
\text { TEST }\end{array}$ & $\begin{array}{c}\text { REFERENCE } \\
\text { STANDARD }\end{array}$ \\
\hline Low & Low & High(PCR) \\
\hline Low & Low & High(PCR) \\
\hline High & Low & High(PCR) \\
\hline Low & Low & High(PCR) \\
\hline Unclear & Low & Low \\
\hline Unclear & Low & High(PCR) \\
\hline Unclear & Low & High(PCR) \\
\hline Low & Low & Low \\
\hline Low & Low & Low \\
\hline High & Low & High(PCR) \\
\hline Low & Low & High(PCR) \\
\hline
\end{tabular}

Figure 2 QUADAS-2 for included studies. (A) QUADAS-2 risk of bias and concerns regarding applicability graph: review authors' judgements about each domain presented as percentages across included studies. (B) QUADAS-2 risk of bias and concerns regarding applicability summary: review authors' judgements about each domain for each included study. QUADAS-2, quality assessment of diagnostic accuracy studies 2.

panel has a sensitivity of greater than 0.90 for all pathogens, while xTAG GPP has a sensitivity between 0.81 and 0.95 for most pathogens. Of note, three pathogens $Y$. enterocolitica, Adenovirus $40 / 41$ and E. histolytica, have exceptionally low sensitivities (0.48-0.70), insufficient for rule out use. Furthermore, xTAG GPP demonstrates a low positive post-test probability for E. histolytica, G. lamblia and Cryptosporidium $(11 \%, 25 \%$, and $40 \%$, respectively) which suggests that XTAG GPP is not accurate in detecting GI parasites. In addition, FilmArray has higher sensitivity and post-test probability than xTAG GPP for most of the pathogens except for Rotavirus A (the posttest probability for positive test is $69 \%$ for FilmArray, $86 \%$ for xTAG). However, there is insufficient data for analysing the accuracy of detecting relatively rare pathogens such as $Y$. enterocolitica and E. histolytica by FilmArray. In contrast, xTAG GPP provides comparable diagnostic accuracy when those pathogens are suspected in clinical conditions and tested. The heterogeneities were high $\left(\mathrm{I}^{2}\right.$ $>50 \%$ ) which may reflect the different study population and gold standards used by the studies. For instance, one study solely included immunocompromised patients ${ }^{4}$ whileChhabra et al included virus positive stool samples ${ }^{2}$ and the other study focused on traveller's diarrhoea. ${ }^{22}$ These studies also used different microbiology techniques as their gold standards such as culture or PCR for bacteria, PCR or EIA for viruses, microscopy or EIA for parasites.
Unlike the conventional PCR test focusing on a single target, both xTAG GPP and FilmArray GI panel employ a syndromic approach to detect multiple pathogens simultaneously. This syndromic approach maximises the use of PCR starting material, uses fewer reagents, and allows increase in time and cost efficiency. ${ }^{23}$

Compared with a previous systematic review, ${ }^{8}$ which includes only two studies for FilmArray and does not provide head-to-head comparisons between FilmArray and xTAG GPP, our updated review includes three additional studies ${ }^{2} 417$ and provides comprehensive quantitative analysis on the comparative accuracy of the two multiplex platforms. The analysis in the previous systematic review ${ }^{8}$ focuses on the comparison of each panel to the standard microbiology technique, and while it introduces prior studies examining agreement between FilmArray and xTAG GPP, does not provide any additional head-to-head quantitative analysis of the two. Our comparative analysis shows FilmArray may perform better than XTAG GPP in detecting certain pathogens which can be explained by the primer design or the open system and technician dependent nature of the xTAG GPP system. The open system increases the risk of amplicon contamination. In particular, xTAG GPP demonstrates relatively lower sensitivity for adenovirus type 40/41 (Sen: 0.70). The low sensitivity may be related to mismatches between the viral templates and the oligonucleotide primers and probes in the system. Furthermore, the reference 
‡

\ मुं

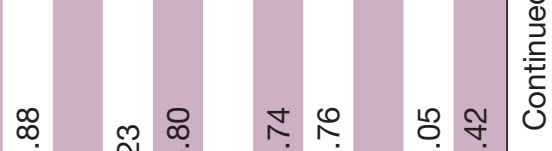

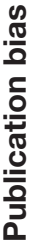

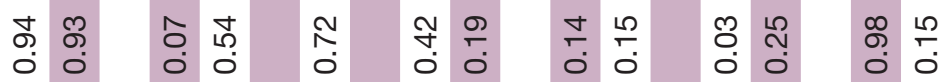

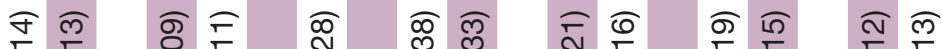

б)

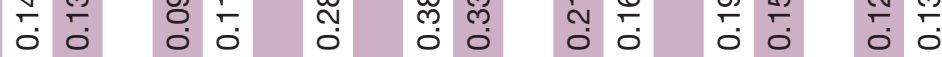

요 우 $ᄋ$

우오

웅

⿸广⿱廿⿻口一亅

¿

ᄂ?

กิ ชิ

Г

\%

우우

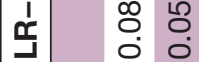

co

¿

อ

¿

กิ กิ

108

ळ

อ

$\stackrel{2}{\circ}$

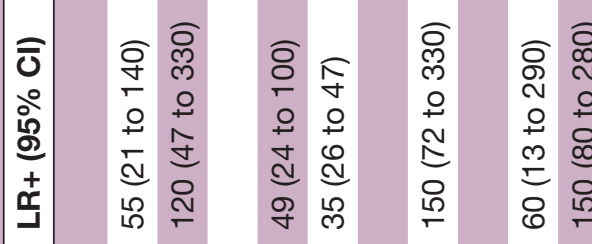

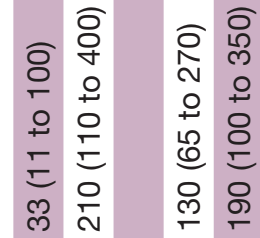

$\circ 0$

ฮิ

유웅

ल등

암 운

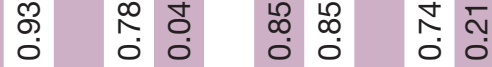

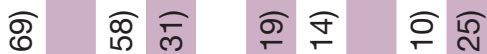

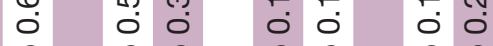

웅ㅇ 우 우아

L

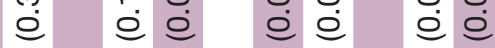

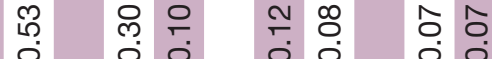

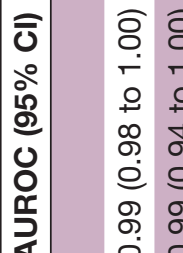

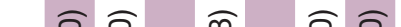

๙

0

옹 จิ

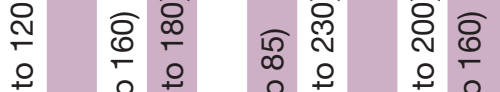

L $\quad$ 눈

迎

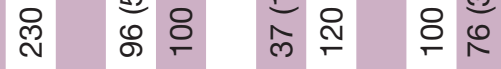

$\circ$

ชิ

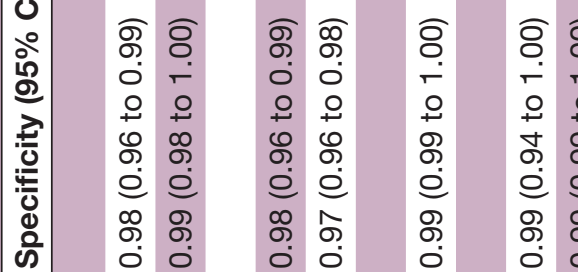

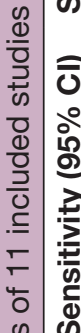

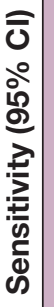

ब

0

هั

$\stackrel{\circ}{\circ}$

ธิ

․

우 우

(5)

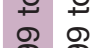

है

눙

क मे मे

¿

ชิ ลิ

อ อ

के 8

8 .

б.

อ 0

우우

용 8

8. 8

○

웅

के

요

อ

ㅇ. 8

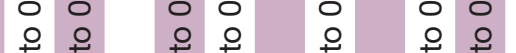

० 0

० 0

๑. :

우

$\circ$ 웅

$\circ$ 웅

$\infty$ 金

б.

ชิ

$\infty$ ऽ

$\begin{array}{cccc}\infty & \infty & \infty & \infty \\ \infty & \infty & \infty & \infty\end{array}$

¿ ¿ $\dot{e}$ ¿

อ อ

อ อ

$\stackrel{0}{0}$

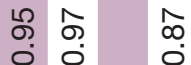

$\begin{array}{ll}\infty & \infty \\ \infty & \text { ก. } \\ 0 & 0\end{array}$

象

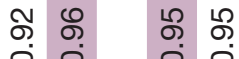

तั

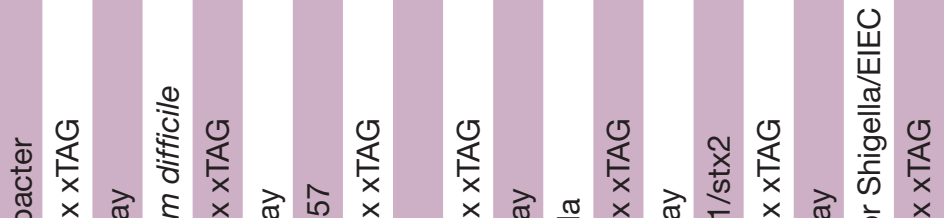

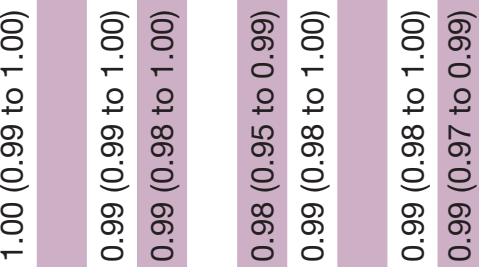

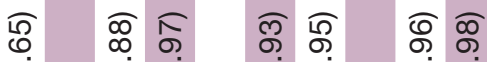

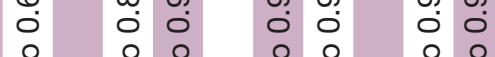

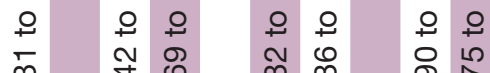
¿ 巳 巳 巳 巳 巳 巳

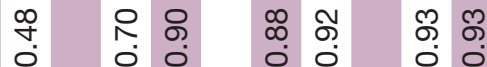


standard real-time PCR does not distinguish between adenovirus species ${ }^{9}$; therefore, it is likely that real-time PCR can detect adenovirus species other than adenovirus type 40/41, resulting in a falsely low sensitivity. For $Y$. enterocolitica, the low sensitivity (48\%) may be impacted by the lowest sensitivity report from Claas $e t a l$; the cause of this low sensitivity needs further verification.

In acute gastroenteritis, careful history questioning the characteristics of the illness and potential exposures can provide powerful diagnostic clues. Clinical features such as shorter duration of illness and frequent vomiting may suggest a viral aetiology. However, an observational study found that there are only a few differences in presentation caused by viral and bacterial pathogens. ${ }^{24}$ Therefore, epidemiological and clinical evaluation are not always reliable methods to differentiate between viral and bacterial etiologies but should be used to guide diagnostic testing. Nowadays, stool culture is the primary diagnostic tool for bacterial gastroenteritis. However, bacterial culture is time-consuming, laborious and costly $y^{25-29}$ and requires selective agars or serologic testing to then identify and confirm the pathogens. Stool culture also has a low positive yield and relatively poor sensitivity ${ }^{30}$ limiting its use in a clinical setting. faecal leucocyte testing (FLT) is another tool often used to screen for infectious diarrhoea. ${ }^{6}$ Although the presence of stool cellular exudates has been long regarded as a sign of infectious diarrhoea, there is evidence questioning the value of FLT. ${ }^{31}$ Investigations show that FLT cannot distinguish between noninfectious gastroenteritis and infectious gastroenteritis inpatient. A study found that in 25 patients with infectious gastroenteritis, only $32 \%$ of patients had positive FLT. ${ }^{32}$ FLT has also been stated to be a poor predictor of C. difficile infection. ${ }^{33}$ In fact, the 2017 Infectious Diseases Society of America Clinical Practice Guidelines does not recommend using FLT to establish the cause of acute infectious diarrhoea. ${ }^{6}$ The inability to determine the specific causative pathogen vastly hinders effective clinical management.

Compared with conventional diagnostic techniques, multiplex technology permits rapid organism-specific diagnostic testing that can curb inappropriate antibiotic use as use of broad-spectrum antibiotics may facilitate the emergence of multidrug resistant bacteria. More importantly, outcomes of some bacterial diarrhoeal illness may worsen with the use of antibiotics. A prospective cohort study found a strong association between antibiotic treatment and the development of the hemolytic-uremic syndrome in children with Escherichia coli O157:H7 infections. ${ }^{34}$ Multiplex assays allow clinicians to make informed decisions and judicious use of antibiotics. Identification of specific pathogens also has public health implications. For instance, infected food workers cause about $70 \%$ of reported norovirus outbreaks from contaminated food. The Centers for Disease Control and Prevention, therefore, recommends food service workers stay home not only at the onset of GI symptoms but also for at least 48 hours after symptoms have resolved. Community 
Open access

Table 3 The calculation of post-test probabilities

\begin{tabular}{|c|c|c|c|c|c|}
\hline Pathogens & Study(n) & $\begin{array}{l}\text { Pre-test probability } \\
(\%)\end{array}$ & Test kit & Likelihood ratio & $\begin{array}{l}\text { Post-test probability } \\
(\%)\end{array}$ \\
\hline \multirow[t]{4}{*}{ Campylobacter } & 11 & 5.6 & Luminex & LR+: 55 (21-140) & 77 \\
\hline & & & & LR-: 0.06 (0.03-0.12) & 0 \\
\hline & 5 & 3.6 & FilmArray & LR+: 120 (47-330) & 82 \\
\hline & & & & LR-: 0.05 (0.02-0.13) & 0 \\
\hline \multirow[t]{4}{*}{ Clostridium difficile } & 8 & 5.5 & Luminex & LR+: 49 (24-100) & 74 \\
\hline & & & & LR-: 0.06 (0.04-0.09) & 0 \\
\hline & 4 & 10.9 & FilmArray & LR+: 35 (26-47) & 81 \\
\hline & & & & LR-: 0.03 (0.01-0.11) & 0 \\
\hline \multirow[t]{2}{*}{ E. coli 0157} & 7 & 0.8 & Luminex & LR+: 150 (72-330) & 55 \\
\hline & & & & LR-: $0.13(0.05-0.28)$ & 0 \\
\hline \multirow[t]{4}{*}{ ETEC } & 5 & 1.2 & Luminex & LR+: 60 (13-290) & 42 \\
\hline & & & & LR-: 0.13 (0.03-0.38) & 0 \\
\hline & 3 & 1.4 & FilmArray & LR+: 150 (80-280) & 68 \\
\hline & & & & LR-: 0.08 (0.02-0.33) & 0 \\
\hline \multirow[t]{4}{*}{ Salmonella } & 11 & 5.3 & Luminex & LR+: 33 (11-100) & 65 \\
\hline & & & & LR-: 0.15 (0.11-0.21) & 1 \\
\hline & 5 & 3.5 & FilmArray & LR+: 210 (110-400) & 88 \\
\hline & & & & LR-: $0.06(0.02-0.16)$ & 0 \\
\hline \multirow[t]{4}{*}{ STEC stx1/stx2 } & 6 & 2.1 & Luminex & LR+: 130 (65-270) & 74 \\
\hline & & & & LR-: 0.08 (0.03-0.19) & 0 \\
\hline & 4 & 3.3 & FilmArray & LR+: 190 (100-350) & 87 \\
\hline & & & & LR-: 0.04 (0.01-0.15) & 0 \\
\hline \multirow[t]{4}{*}{ Shigella/EIEC } & 11 & 4.3 & Luminex & LR+: 73 (37-150) & 77 \\
\hline & & & & LR-: 0.07 (0.04-0.13) & 0 \\
\hline & 4 & 4.8 & FilmArray & LR+: 440 (170-1200) & 96 \\
\hline & & & & LR-:0.05 (0.02-0.13) & 0 \\
\hline \multirow[t]{2}{*}{ Yersinia enterocolitica } & 3 & 2.1 & Luminex & LR+: 230 (45-1200) & 83 \\
\hline & & & & LR-: 0.53 (0.35-0.69) & 1 \\
\hline \multirow[t]{4}{*}{ Adenovirus $40 / 41$} & 9 & 2 & Luminex & LR+: 96 (53-160) & 66 \\
\hline & & & & LR-: 0.30 (0.12-0.58) & 1 \\
\hline & 5 & 3.8 & FilmArray & LR+: 100 (55-180) & 80 \\
\hline & & & & LR-: 0.10 (0.03-0.31) & 0 \\
\hline \multirow[t]{4}{*}{ Norovirus GI/GII } & 10 & 6.1 & Luminex & LR+: $37(16-85)$ & 71 \\
\hline & & & & LR-: 0.12 (0.08-0.19) & 1 \\
\hline & 6 & 6.8 & FilmArray & LR+: 120 (61-230) & 90 \\
\hline & & & & LR-: 0.08 (0.05-0.14) & 1 \\
\hline \multirow[t]{4}{*}{ Rotavirus A } & 11 & 5.7 & Luminex & LR+: 100 (52-200) & 86 \\
\hline & & & & LR-: 0.07 (0.04-0.10) & 0 \\
\hline & 6 & 2.9 & FilmArray & LR+: 76 (35-160) & 69 \\
\hline & & & & LR-: $0.07(0.02-0.25)$ & 0 \\
\hline \multirow[t]{4}{*}{ Cryptosporidium } & 7 & 0.7 & Luminex & LR+: $96(22-410)$ & 40 \\
\hline & & & & LR-: 0.18 (0.08-0.37) & 0 \\
\hline & 3 & 1.2 & FilmArray & LR+: $230(110-490)$ & 74 \\
\hline & & & & LR-: 0.08 (0.02-0.32) & 0 \\
\hline
\end{tabular}

Continued 
Table 3 Continued

\begin{tabular}{|c|c|c|c|c|c|}
\hline Pathogens & Study(n) & $\begin{array}{l}\text { Pre-test probability } \\
(\%)\end{array}$ & Test kit & Likelihood ratio & $\begin{array}{l}\text { Post-test probability } \\
(\%)\end{array}$ \\
\hline \multirow[t]{2}{*}{ Entamoeba histolytica } & 6 & 0.2 & Luminex & LR+: 59 (18-160) & 11 \\
\hline & & & & LR-: 0.30 (0.08-0.68) & 0 \\
\hline \multirow[t]{4}{*}{ Giardia lamblia } & 7 & 0.9 & Luminex & LR+: 36 (13-85) & 25 \\
\hline & & & & LR-: 0.19 (0.06-0.49) & 0 \\
\hline & 4 & 1.3 & FilmArray & LR+: 200 (100-390) & 72 \\
\hline & & & & LR-: 0.09 (0.02-0.31) & 0 \\
\hline \multirow[t]{2}{*}{ Astrovirus } & 3 & 2.7 & FilmArray & LR+: 300 (55-1600) & 89 \\
\hline & & & & LR-: $0.04(0.01-0.15)$ & 0 \\
\hline \multirow[t]{2}{*}{ Sapovirus } & 3 & 5.6 & FilmArray & LR+: 170 (66-430) & 91 \\
\hline & & & & LR-: $0.04(0.01-0.17)$ & 0 \\
\hline
\end{tabular}

fecal-oral outbreaks or waterborne outbreaks, on the other hand, have been associated with Giardia, Cryptosporidium and norovirus. ${ }^{35}$ The high rule-out value of FilmArray GI panel means that it can quickly detect highly communicable pathogens and prevent widespread transmission.

It has to be noted that most cases of acute gastroenteritis are of infectious aetiology and resolve with symptomatic treatment alone. ${ }^{6}$ It is neither practical nor cost-effective to perform an extensive laboratory evaluation for every patient presenting with diarrhoeal illness. It is crucial, however, to make accurate microbial identification and enact specific directed therapy in patients who are more likely to have a bacterial infection or who would need treatment once the organism is identified; this includes patients with signs of severe illness (dehydration, severe abdominal pain) or inflammatory diarrhoea (bloody stools, fevers) and patients with high-risk features, comorbidities and immunocompromised conditions. ${ }^{36}$ For example, in patients with clinically significant diarrhoea, suspected $C$. difficile infection, laboratory approach with nucleic acid amplification testing (NAAT) alone or multistep algorithm including initial EIA screening for glutamate dehydrogenase antigen and toxins $\mathrm{A}$ and $\mathrm{B}$ arbitrated by NAAT is recommended in recent guidelines. ${ }^{37}$ Furthermore, in patients with severe or fulminant colitis, multiplex assays may improve outcomes as early surgical consultation and timely operative management result in a shorter hospital length of stay if a patient's clinical course worsens ${ }^{38}$. Implementing multiplex assays remarkably reduces the time to initial identification of pathogens. Randomised controlled trials in patients with shigellosis have demonstrated that appropriate use of antimicrobial therapy shortens the average duration of diarrhoea by 2.4 days or more, decreases the duration of fever and tenesmus and reduces the excretion of infectious organisms. ${ }^{39}$ Altogether, prompt pathogen-specific diagnosis through multiplex assays could greatly influence clinical courses by earlier initiation of appropriate therapy and thereby preventing potential complications in the most vulnerable patients. In addition to generating more favourable clinical outcomes, multiplex assays can also optimise infection control, allowing for implementation of timely measures to mitigate nosocomial transmission and outbreaks. ${ }^{40}$

Although this meta-analysis includes more than 7000 samples with robust statistical analysis following the Cochrane guideline, there are still several limitations. First, the relative few data on FilmArray did not allow us to perform subgroup analyses for some rare but deadly pathogens (eg, Vibrio cholerae, Enteroaggregative E. coli, Enteropathogenic E. coli, Cyclospora cayetanensis and E. histolytica). Second, the patient characteristics varied among the included studies in age, travel history and symptoms, and the number of the studies may be insufficient to perform several sensitivity analyses. Third, the accuracy of the nucleic acid test reflected by our study does not reflect active infection. Laboratory results should always be interpreted with a high degree of clinical correlation. ${ }^{41}$ Fourth, five studies included discordant analysis which may increase the sensitivity and specificity due to the potential elevation of true positive and true negative cases. In addition, although the FilmArray GI panel shows a higher overall summary AUROC than xTAG GI panel (AUROC 0.99 vs $0.98, \mathrm{p}=0.03$ ), the result should only be viewed as a statistical significance instead of clinical meaning. Despite these limitations, our results yield valuable insight into the accuracy of xTAG GPP and FilmArray GI panel and their utility in clinical practice.

\section{CONCLUSION}

In summary, this is the first systematic review and metaanalysis comparatively evaluating the performance of the novel multiplex PCR-based tests Luminex xTAG GPP and FilmArray GI panel in detecting each pathogen. Compared with conventional methodologies, xTAG GPP and FilmArray GI panel can detect more than $90 \%$ of the common enteropathogens with high sensitivity, specificity and a shorter turnaround time. In addition, FilmArray 
has higher sensitivity and post-test probability than xTAG GPP for most of the pathogens except for Rotavirus $\mathrm{A}$ (the post-test probability for positive test is $69 \%$ for FilmArray, $86 \%$ for xTAG). Multiplex platforms can clearly have a significant impact on patient management with the potential to (1) reduce the time to first identification of a pathogen, (2) influence patient outcome through early initiation of therapy, (3) alter antimicrobial stewardship and (4) optimise infection control. It is important, however, to account for the variable rule-out accuracy of xTAG GPP and its suboptimal diagnostic accuracy for parasites. However, five studies included in our evaluation had discordant analysis which may increase the sensitivity and specificity due to the potential elevation of true positive and true negative cases. Regardless, this will be an exciting area of development and research as multiplex technology becomes increasingly integrated into everyday clinical practice in the future.

\section{Further reading}

Centers for Disease Control and Prevention (CDC). Multisite outbreak of norovirus associated with a franchise restaurant-Kent County, Michigan, May 2005. Morbidity and Mortality Weekly Report 2006;55:395-7.

\section{Author affiliations}

${ }^{1}$ Department of Medical Education, National Taiwan University Hospital, Taipei, Taiwan

${ }^{2}$ Department of Medicine, Mount Sinai Morningside Hospital, New York, New York, USA

${ }^{3}$ Department of Medicine, Brown University Warren Alpert Medical School, Providence, Rhode Island, USA

${ }^{4}$ Internal Medicine, Brown University Division of Biology and Medicine, Providence, Rhode Island, USA

${ }^{5}$ Department of Epidemiology, Harvard University T H Chan School of Public Health, Boston, Massachusetts, USA

${ }^{6}$ Medical Wizdom, LLC, Brooklinw, MA, USA

${ }^{7}$ Department of Medical Engineering, College of Engineering, Cornell University, Ithaca, New York, USA

${ }^{8}$ Department of Computer Science, College of Engineering, Cornell University, Ithaca, NY, USA

${ }^{9}$ Department of Emergency Medicine, National Taiwan University Hospital, Taipei, Taiwan

${ }^{10}$ Department of Pediatric Emergency Medicine and Medical Research, China Medical University Children's Hospital, Taichung, Taiwan

${ }^{11}$ Department of Medicine, School of Medicine, China Medical University, Taichung, Taiwan

${ }^{12}$ Center of Intelligent Healthcare, National Taiwan University Hospital, Taipei, Taiwan

${ }^{13}$ Byers Center for Biodesign, Stanford University, Stanford, CA, USA

Acknowledgements We thank the staff of the Core Labs at the Department of Medical Research in National Taiwan University Hospital for technical support, Medical Wizdom, USA for technical assistance in statistical analysis.

Contributors C-CL had full access to all the data in the study and takes responsibility for the integrity of the data and the accuracy of the data analysis. C-CL designed the study, obtained funding, drafted the analytical plan, guided the statistical analysis, interpreted the data, and critically revised the manuscript. $\mathrm{L}-\mathrm{JC}$ and $\mathrm{CH}$ were responsible for drafting the manuscript, collection of data, interpretation of the results, and critical revision of the manuscript. BC contributed to data interpretation, writing the manuscript and provided critical revisions. T-YL, JD and VS-0 drafted the manuscript, interpreted the data, and critically revised the manuscript. W-TH were involved in the design of study, and responsible for statistical analysis, interpretation of the data and critical revision of the manuscript. $\mathrm{K}-\mathrm{YS}$ was responsible for statistical analysis, interpretation of the data and critical revision of the manuscript. S-TC and H-PW reviewed the manuscript and provided insights in the contents. All investigators contributed to the design or execution of the study, and approved the final version.

Funding The authors have not declared a specific grant for this research from any funding agency in the public, commercial or not-for-profit sectors.

Competing interests None declared.

Patient consent for publication Not required.

Provenance and peer review Not commissioned; externally peer reviewed.

Data availability statement Data are available on reasonable request. All data relevant to the study are included in the article or uploaded as online supplemental information. All relevant data are available from the corresponding author at hit3transparency@gmail.com.

Supplemental material This content has been supplied by the author(s). It has not been vetted by BMJ Publishing Group Limited (BMJ) and may not have been peer-reviewed. Any opinions or recommendations discussed are solely those of the author(s) and are not endorsed by BMJ. BMJ disclaims all liability and responsibility arising from any reliance placed on the content. Where the content includes any translated material, BMJ does not warrant the accuracy and reliability of the translations (including but not limited to local regulations, clinical guidelines, terminology, drug names and drug dosages), and is not responsible for any error and/or omissions arising from translation and adaptation or otherwise.

Open access This is an open access article distributed in accordance with the Creative Commons Attribution Non Commercial (CC BY-NC 4.0) license, which permits others to distribute, remix, adapt, build upon this work non-commercially, and license their derivative works on different terms, provided the original work is properly cited, appropriate credit is given, any changes made indicated, and the use is non-commercial. See: http://creativecommons.org/licenses/by-nc/4.0/.

\section{ORCID iDs}

Li-Jun Chang http://orcid.org/0000-0002-6348-6496

Chun-Jen Hsiao http://orcid.org/0000-0002-3048-4312

Bing Chen http://orcid.org/0000-0002-6058-9529

Tzu-Yu Liu http://orcid.org/0000-0001-8348-620X

Julia Ding http://orcid.org/0000-0001-6738-4713

Wan-Ting Hsu http://orcid.org/0000-0002-6677-0951

Victor Su-Ortiz http://orcid.org/0000-0002-8282-2272

Szu-Ta Chen http://orcid.org/0000-0002-9715-1221

Chien-Chang Lee http://orcid.org/0000-0002-1243-2463

\section{REFERENCES}

1 Farthing M, Salam MA, Lindberg G, et al. Acute diarrhea in adults and children: a global perspective. J Clin Gastroenterol 2013;47:12-20.

2 Chhabra P, Gregoricus N, Weinberg GA, et al. Comparison of three multiplex gastrointestinal platforms for the detection of gastroenteritis viruses. J Clin Virol 2017:95:66-71.

3 Dryden MS, Gabb RJ, Wright SK. Empirical treatment of severe acute community-acquired gastroenteritis with ciprofloxacin. Clin Infect Dis 1996;22:1019-25.

4 Alejo-Cancho I, Fernández Avilés F, Capón A, et al. Evaluation of a multiplex panel for the diagnosis of acute infectious diarrhea in immunocompromised hematologic patients. PLoS One 2017; 12:e0187458.

5 Duong VT, Phat VV, Tuyen HT, et al. Evaluation of Luminex xTAG gastrointestinal pathogen panel assay for detection of multiple diarrheal pathogens in fecal samples in Vietnam. J Clin Microbiol 2016;54:1094-100.

6 Shane AL, Mody RK, Crump JA, et al. 2017 infectious diseases Society of America clinical practice guidelines for the diagnosis and management of infectious diarrhea. Clin Infect Dis 2017;65:e45-80.

7 Beckmann $\mathrm{C}$, Heininger U, Marti H, et al. Gastrointestinal pathogens detected by multiplex nucleic acid amplification testing in stools of pediatric patients and patients returning from the tropics. Infection 2014:42:961-70.

8 Freeman K, Mistry H, Tsertsvadze A, et al. Multiplex tests to identify gastrointestinal bacteria, viruses and parasites in people with suspected infectious gastroenteritis: a systematic review and economic analysis. Health Technol Assess 2017;21:1-188 https:// www.journalslibrary.nihr.ac.uk/hta/hta21230\#/full-report

9 Claas EC, Burnham C-AD, Mazzulli T, et al. Performance of the XTAG $®$ gastrointestinal pathogen panel, a multiplex molecular assay 
for simultaneous detection of bacterial, viral, and parasitic causes of infectious gastroenteritis. J Microbiol Biotechnol 2013;23:1041-5.

10 Khare R, Espy MJ, Cebelinski E, et al. Comparative evaluation of two commercial multiplex panels for detection of gastrointestinal pathogens by use of clinical stool specimens. J Clin Microbiol 2014;52:3667-73.

11 Leeflang MMG, Deeks JJ, Gatsonis C, et al. Systematic reviews of diagnostic test accuracy. Ann Intern Med 2008;149:889.

12 Mclnnes MDF, Moher D, Thombs BD, et al. Preferred reporting items for a systematic review and meta-analysis of diagnostic test accuracy studies: the PRISMA-DTA statement. JAMA 2018;319:388-96.

13 Whiting PF, Rutjes AWS, Westwood ME, et al. QUADAS-2: a revised tool for the quality assessment of diagnostic accuracy studies. Ann Intern Med 2011;155:529.

14 Arends LR, Hamza TH, van Houwelingen JC, et al. Bivariate random effects meta-analysis of ROC curves. Med Decis Making 2008;28:621-38.

15 Harbord RM, Whiting P, Sterne JAC, et al. An empirical comparison of methods for meta-analysis of diagnostic accuracy showed hierarchical models are necessary. J Clin Epidemiol 2008;61:1095-103.

16 Higgins JPT, Thompson SG, Deeks JJ, et al. Measuring inconsistency in meta-analyses. BMJ 2003;327:557-60.

17 Huang RSP, Johnson CL, Pritchard L, et al. Performance of the Verigene $\AA$ enteric pathogens test, BioFire FilmArray ${ }^{\mathrm{TM}}$ gastrointestinal panel and Luminex XTAG® gastrointestinal pathogen panel for detection of common enteric pathogens. Diagn Microbiol Infect Dis 2016;86:336-9.

18 Buss SN, Leber A, Chapin K, et al. Multicenter evaluation of the BioFire FilmArray gastrointestinal panel for etiologic diagnosis of infectious gastroenteritis. J Clin Microbiol 2015;53:915-25.

19 Deng J, Luo X, Wang R, et al. A comparison of Luminex XTAG® gastrointestinal pathogen panel (xTAG Gpp) and routine tests for the detection of enteropathogens circulating in southern China. Diagn Microbiol Infect Dis 2015;83:325-30.

20 Halligan E, Edgeworth J, Bisnauthsing K, et al. Multiplex molecular testing for management of infectious gastroenteritis in a hospital setting: a comparative diagnostic and clinical utility study. Clinical Microbiology and Infection 2014;20:0460-7.

21 Mengelle C, Mansuy JM, Prere MF, et al. Simultaneous detection of gastrointestinal pathogens with a multiplex Luminex-based molecular assay in stool samples from diarrhoeic patients. Clin Microbiol Infect 2013;19:E458-65.

22 Zboromyrska Y, Hurtado JC, Salvador P, et al. Aetiology of traveller's diarrhoea: evaluation of a multiplex PCR tool to detect different enteropathogens. Clin Microbiol Infect 2014;20:0753-9.

23 Hockman D, Dong M, Zheng $\mathrm{H}$, et al. Comparison of multiplex PCR hybridization-based and singleplex real-time PCR-based assays for detection of low prevalence pathogens in spiked samples. $J$ Microbiol Methods 2017;132:76-82.

24 Bresee JS, Marcus R, Venezia RA, et al. The etiology of severe acute gastroenteritis among adults visiting emergency departments in the United States. J Infect Dis 2012;205:1374-81.
25 Bennett WE, Tarr PI. Enteric infections and diagnostic testing. Curr Opin Gastroenterol 2009;25:1-7.

26 Dusch $\mathrm{H}$, Altwegg M. Evaluation of five new plating media for isolation of Salmonella species. J Clin Microbiol 1995;33:802-4.

27 Gaillot O, di Camillo P, Berche P, et al. Comparison of CHROMagar Salmonella medium and Hektoen enteric agar for isolation of salmonellae from stool samples. J Clin Microbiol 1999;37:762-5.

28 Perez JM, Cavalli P, Roure C, et al. Comparison of four chromogenic media and Hektoen agar for detection and presumptive identification of Salmonella strains in human stools. J Clin Microbiol 2003;41:1130-4.

29 Perry JD, Ford M, Taylor J, et al. Abc medium, a new chromogenic agar for selective isolation of Salmonella spp. J Clin Microbiol 1999;37:766-8

30 Guerrant RL, Van Gilder T, Steiner TS, et al. Practice guidelines for the management of infectious diarrhea. Clin Infect Dis 2001;32:331-51.

31 Willmore J, Shearman C. On the differential diagnosis of the dysenteries: the diagnostic value of the cell-exudate in the stools of acute am\$oelig;bic and bacillary dysentery. The Lancet 1918;192:200-6.

32 Granville LA, Cernoch P, Land GA, et al. Performance assessment of the fecal leukocyte test for inpatients. J Clin Microbiol 2004;42:1254-6.

33 Reddymasu S, Sheth A, Banks DE. Is fecal leukocyte test a good predictor of Clostridium difficile associated diarrhea? Ann Clin Microbiol Antimicrob 2006;5:9.

34 Wong CS, Jelacic S, Habeeb RL, et al. The risk of the hemolyticuremic syndrome after antibiotic treatment of Escherichia coli O157:H7 infections. N Engl J Med 2000;342:1930-6.

35 Regina L, Jason $\mathrm{BH}$. Approach to the adult with acute diarrhea in resource-rich settings.

36 Riddle MS, DuPont HL, Connor BA. Acg clinical guideline: diagnosis treatment, and prevention of acute diarrheal infections in adults. Am J Gastroenterol 2016;111:602-22.

37 McDonald LC, Gerding DN, Johnson S, et al. Clinical practice guidelines for Clostridium difficile infection in adults and children: 2017 update by the infectious diseases Society of America (IDSA) and Society for healthcare epidemiology of America (SheA). Clin Infect Dis 2018;66:e1-48.

38 van der Wilden GM, Velmahos GC, Chang Y, et al. Effects of a new hospital-wide surgical consultation protocol in patients with Clostridium difficile colitis. Surg Infect 2017;18:563-9.

39 Tong MJ, Martin DG, Cunningham JJ, et al. Clinical and bacteriological evaluation of antibiotic treatment in shigellosis. JAMA 1970;214:1841-4.

40 Kahlau P, Malecki M, Schildgen V, et al. Utility of two novel multiplexing assays for the detection of gastrointestinal pathogens a first experience. Springerplus 2013;2:106.

41 Binnicker MJ. Multiplex molecular panels for diagnosis of gastrointestinal infection: performance, result interpretation, and cost-effectiveness. J Clin Microbiol 2015;53:3723-8. 